15. Fishbein MC, Meerbaum S, Rit J, Lando U, Kanmatsuse $\mathbf{K}$ Mercier JC, Corday E, Ganz W: Early phase acute myocardial infarct size quantification: Validation of the triphenyl tetrazolium chloride tissue enzyme staining technique. AM HEART J 101:593, 1981.

16. Mallory GK, White PD, Salcedo-Salgar J: The speed of healing of myocardial infarctions. A study of the pathological anatomy in 72 cases. AM Heart J 18:647, 1939.

17. Jennings RB, Ganote CE: Structural changes in myocardium during acute ischemia. Circ Res 35(Suppl III):156, 1974.

18. Kloner RA, Ganote CF, Whalen DA Jr, Jennings RB: Effect of a transient period of ischemia on myocardial cells. II. Fine structure during the first few minutes of reflow. Am J Pathol 74:399, 1974

19. Lang T, Corday E, Gold H, Meerbaum S, Rubins S, Constantini C, Hirose S, Osher J, Rosen V: Consequences of reperfusion after coronary occlusion. Am J Cardiol 33:69, 1974.

20. Fishbein MC, Y-Rit J, Lando U, Kanmatsuse K, Mercier JC, Ganz W: The relationship of vascular injury and myocardial hemorrhage to necrosis after reperfusion. Circulation 62:1274, 1980 .
21. Kloner RA, Rude RE, Carlson N, Maroko PR, DeBoer LWV, Braunwald E: Ultrastructural evidence of microvascular damage and myocardial cell injury after coronary artery occlusion: Which comes first? Circulation 62:945, 1980.

22. Higginson, LAJ, White F, Heggtveit HA, Sanders TM, Bloor CM, Covell JW: Determinants of myocardial hemorrhage after coronary reperfusion in the anesthetized dog. Circulation 65:62, 1982.

23. Darsee JR, Kloner RA: The no reflow phenomenon: A time-limiting factor for reperfusion after coronary occlusion. Am J Cardiol 46:800, 1980.

24. Fishbein MC, Maclean D, Maroko PR: The histopathologic evolution of myocardial infarction. Chest 73:843, 1978.

25. Vatner SF, Baig H, Manders WT, Maroko PR: Effects of coronary artery reperfusion on myocardial infarct size calculated from creatine kinase. J Clin Invest 61:1048, 1978.

26. Reimer KA, Jennings RB: The "wavefront phenomenon" of myocardial ischemic cell death. Transmural progression of necrosis within the framework of ischemic bed size (myocardium at risk) and collateral flow. Lab Invest 40:633, 1979.

\title{
The beneficial effects of nafazatrom (BAYg6575) on experimental coronary thrombosis
}

An in vivo model of coronary artery thrombosis in the conscious dog was used to evaluate the potential antithrombotic effect of nafazatrom (BAYg6575). A silver wire electrode was implanted in the left circumflex coronary artery (LCX) and was used at a later time to deliver a 50 uA anodal current for $\mathbf{2 4}$ hours to the intimal surface of the vessel. The resulting injury to the endothelium was accompanied by the adhesion, aggregation, and subsequent formation of an occlusive thrombus in the LCX of vehicle-treated dogs. Nafazatrom was given as an intravenous dose of $1 \mathrm{mg} / \mathrm{kg}$ for 48 hours, before anodal stimulation of the coronary artery was initiated, and was repeated every 6 hours during anodal stimulation for a total treatment period of 72 hours. As compared to vehicle-treated control dogs, the dogs treated with nafazatrom had smaller thrombi, preservation of coronary blood flow, a lesser degree of ischemic injury in the myocardial region subserved by the LCX, and less frequent premature ventricular complexes during the final 12 hours of the study period. Concomitant ex vivo platelet aggregation studies revealed significant inhibition of platelet aggregation in response to collagen and adenosine diphosphate in drug-treated dogs. The results of these investigations provide evidence that nafazatrom prevents in vivo development of occlusive coronary artery thrombi in response to disruption of the endothelial surface of the vessel. (Am HEART J 107:629, 1984.)

\section{J. Shea, E. M. Driscoll, J. L. Romson, B. Pitt, and B. R. Lucchesi}

Ann. Arbor, Mich.

From the Departments of Pharmacology and Internal Medicine (Cardiology), University of Michigan Medical School.

Supported by grant HL-27817 from the National Heart, Lung, and Blood Institute, by a grant-in-aid from Miles Laboratories, a fellowship from the Michigan Heart Association (Dr. Shea), and a Fellowship from the Pharmaceutical Manufacturer's Association Foundation (Dr. Romson).

Received for publication Sept. 30, 1982; revision received Dec. 27, 1982; accepted Jan. 7, 1983.

Reprint requests: Benedict R. Lucchesi, Ph.D., M.D., Department of Pharmacology, The University of Michigan Medical School, M6322 Medical Science Ruilding, Ann Arbor, MI 48109
Preliminary work on nafazatrom suggested that this compound may act as a stimulator of prostacyclin release from the vessel wall. ${ }^{1}$ More recently, evidence suggests that nafazatrom may inhibit not only the prostacyclin degrading enzyme, ${ }^{2}$ but tissue and platelet lipoxygenases as well. ${ }^{3}$ In addition, this drug may also act as a free radical scavenger. ${ }^{3}$ In animals and humans, nafazatrom has had no effect on hemodynamics, blood coagulation, fibrinolysis, or 


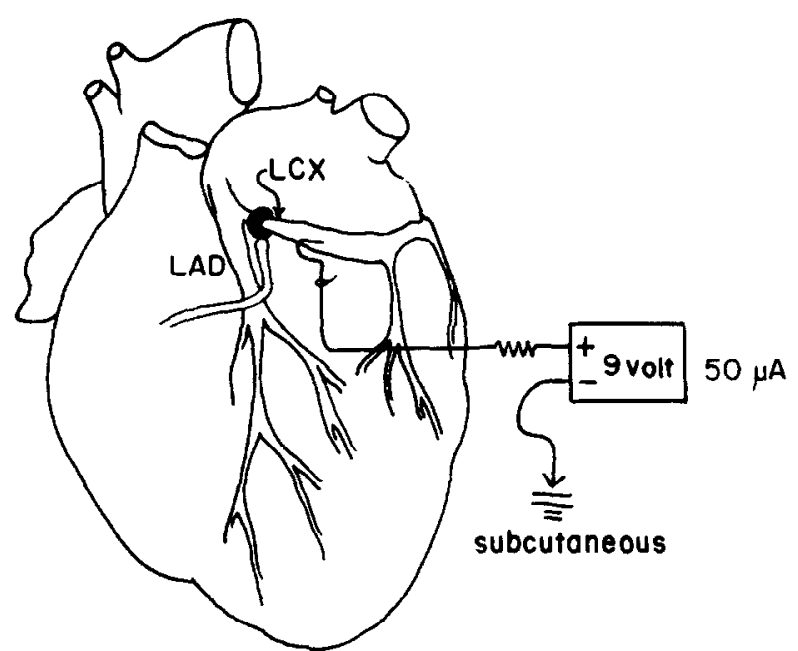

Fig. 1. Schematic drawing indicating position of the wire electrode in the left circumflex coronary artery ( $L C X)$ and the position of the electromagnetic flow probe placed proximally on the LCX.

platelet aggregation in vitro. ${ }^{1,4} \mathrm{Nafazatrom}$ has been effective in the prevention of experimental thrombosis caused by traumatically induced damage of vessel segments in the rat carotid artery and rabbit femoral artery. ${ }^{4}$ In the same models, nafazatrom has thrombolytic activity comparable to that of urokinase, although the mechanism is unclear. ${ }^{4} \mathrm{~A}$ recent report on streptozocin-induced diabetic rats indicated that the decreased aortic production of prostacyclin could be increased by administration of nafazatrom. ${ }^{5}$

In view of the promising antithrombotic potential of nafazatrom, we investigated this drug in a conscious canine model of experimental coronary thrombosis. ${ }^{6}$ This model is appealing as it minimizes the effect of "physiologic reactance" as a result of general anesthesia and surgical stress. ${ }^{7}$ As a result, the cardiovascular, neural, and other physiologic responses more closely resemble the clinical state. In addition, pharmacologic doses of drugs easily tolerated by the anesthetized animal are often poorly tolerated by the conscious animal; thus the dosages of a drug given to the conscious animal will more closely resemble the clinical situation. In the present study, nafazatrom reduced the size of coronary thrombi as compared to control animals while maintaining coronary blood flow. As a consequence of these effects, the extent of myocardial ischemic injury and frequency of ventricular arrhythmias in the last 12 hours of study were reduced in the drug-treated animals. We also found significant inhibition of ex vivo platelet aggregation in nafazatrom-treated animals.

\section{METHODS}

Surgical procedure. Male mongrel dogs, 15 to $20 \mathrm{~kg}$, were anesthetized with intravenous sodium pentobarbital $(30 \mathrm{mg} / \mathrm{kg})$ and artificially respirated. A lead II ECG was monitored throughout surgery. By means of aseptic technique, cannulae were placed in the left common carotid artery and jugular vein, then exteriorized through the nape of the neck. After left thoracotomy, the heart was suspended in a pericardial cradle and the proximal left circumflex coronary artery (LCX) was isolated from the surrounding tissues. A 28-gauge Teflon-coated silver wire with $5 \mathrm{~mm}$ of the tip of a 25-gauge hypodermic needle secured on the wire's leading end was inserted into the LCX and affixed to the heart with suture. An electromagnetic flow probe (Carolina Instrument Co.), precalibrated with whole hlood, was placed on the LCX 2 to $3 \mathrm{~mm}$ proximal to the silver wire insertion and affixed to the heart (Fig. 1). Zero flow and calibration were established by transient total occlusion of the LCX followed by release. Coronary blood flow was measured with a squarewave electromagnetic flow meter (Carolina Medical Electronics, Inc.). The pericardium and chest were closed in layers. Grass disc electrodes were tunneled subcutaneously near the right foreleg and left hindleg, and were exteriorized along with the intracoronary wire and flow probe through the thoracotomy incision. The dogs were given a single intramuscular injection of ampicillin (3 $\mathrm{mg} / \mathrm{kg}$ ). Cannulae were flushed repeatedly with saline solution to maintain patency.

Electrical stimulation of LCX and drug treatment. On the morning after surgery, the animal's heart rate, blood pressure, ECG, and coronary blood flow were monitored. Animals were studied further only if: (1) they were free of ECG evidence of myocardial injury; (2) they had no evidence of significant arrhythmias (fewer than five premature ventricular contractions per minute; (3) they had a normal phasic pattern of coronary blood flow; and (4) they were fully recovered from surgery and ambulatory. Venous blood was drawn from a foreleg for platelet studies (vide infra). Nafazatrom, $1 \mathrm{mg} / \mathrm{kg}$, or saline solution was administered intravenously every 6 hours for a total of 12 doses ( 3 days). The nafazatrom was dissolved in 1 to $2 \mathrm{ml}$ of $0.1 \mathrm{~N} \mathrm{NaOH}$ and diluted with saline solution to a final standard volume of $20 \mathrm{ml}(\mathrm{pH} \mathrm{9)}$. The control solutions of normal saline had 1 to $2 \mathrm{ml}$ of $\mathrm{NaOH}$ included in the $20 \mathrm{ml}$ injected volume. Animals were given drugs or control solutions according to a random number table.

After the fifth dose of drug or saline solution, venous blood was again drawn for platelet studies. After the eighth dose of drug or saline solution, anodal current from a 9-volt battery was delivered to the intimal surface of the LCX via the Teflon-coated wire. The current output of 50 uA was adjusted through a $250,000 \mathrm{ohm}$ potentiometer placed in series. The subcutaneous electrodes were connected to a telemetry transmitter for transmission of the ECG signal. The potentiometer with battery and transmitter was held in a nylon jacket thus allowing the dog unrestricted movement. ECG data were received via telemetry and in turn were recorded by an FM-tape 


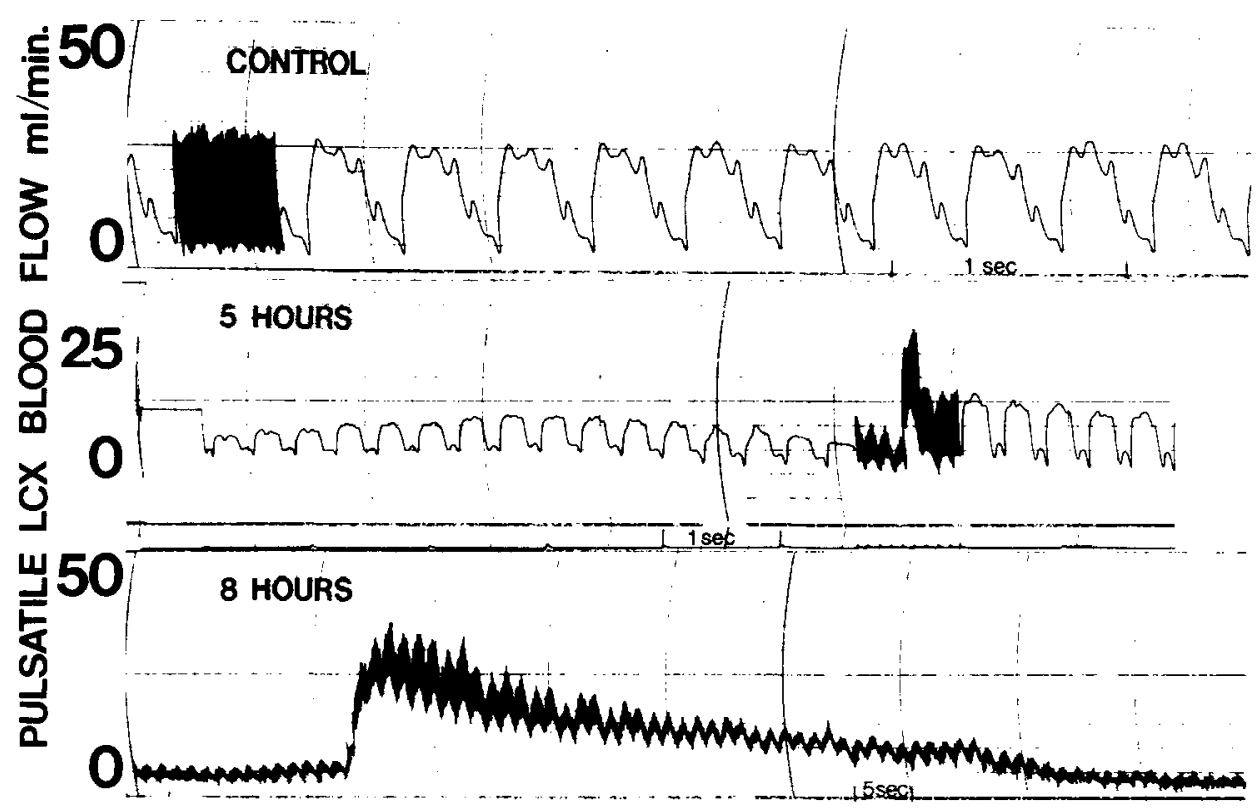

Fig. 2. Representative example of the pulsatile and mean left circumflex coronary artery $(L C X)$ blood flows in response to intraluminal electrical stimulation. Multiple reductions in flow are followed by reactive hyperemic responses with eventual total absence of flow.

recorder (Cardiocassette) programmed to cycle for 28 seconds every 15 minutes. The tape was played back later into a Grass polygraph for analysis of arrhythmias. The 50 uA current to the LCX was maintained for 24 hours and then discontinued. Venous blood was again drawn for platelet studies. The animals were monitored briefly for heart rate, blood pressure, ECG, and coronary blood flow. The animals were then anesthetized with sodium pentobarbital and the heart was exposed as described previously. Ventricular fibrillation was induced by DC current and the heart was removed. The LCX in the area of the wire insertion was dissected free and the artery was opened lengthwise. The wet thrombus was removed from the intima and weighed. The heart was then "bread-loafed" from apex to base into $0.7 \mathrm{~cm}$ thick transverse slices and incubated in 2,3,5-triphenyltetrazolium chloride (Sigma) for 30 minutes at $37^{\circ} \mathrm{C}$. This dye stains normal tissues brick red by virtue of its reaction with myocardial dehydrogenases, while unstained irreversibly injured tissue appears pale. Both the nonstained and stained areas were removed and weighed so as to obtain a measurement of the extent of irreversible ischemic injury.

Platelet aggregation studies. Platelet aggregation studies were performed by means of previously described spectrophotometric methods, ${ }^{8}$ utilizing a Bio/Data platelet aggregometer. Platelet-rich plasma was prepared by collecting venous blood in $1.0 \mathrm{ml}$ of $3.8 \%$ sodium citrate to a total volume of $10 \mathrm{ml}$. This was centrifuged at $310 \times \mathrm{g}$ for 3 minutes to obtain the platelet-poor plasma fraction. Platelet-rich plasma was diluted with platelet-poor plasma to a platelet count of $200,000 / \mathrm{mm}^{3}$ before use in the aggregation assays. All platelet samples were assayed

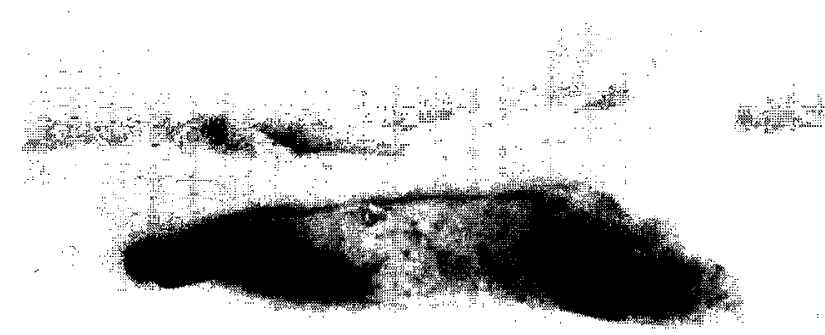

Fig. 3. Typical LCX thrombus in situ at the end of the 24-hour period of electrical injury of the LCX.

within 1 hour of the time of phlebotomy. Aggregation was initiated under three different conditions with the use of a $50 \mu \mathrm{l}$ aliquot of aggregating agent added to $450 \mu \mathrm{l}$ of diluted platelet-rich plasma. Aggregating conditions included: collagen (1:80 dilution of Ethicon collagen dispersion-TD150), $5.0 \mu \mathrm{g}$ adenosine diphosphate (Sigma), and arachidonic acid (Sigma) $0.65 \mathrm{mM}$ with an additional $10 \mu \mathrm{l}$ of L-epinephrine (Sigma), $0.55 \mu \mathrm{M}$ in saline solution at $\mathrm{pH} 3$.

Statistics. All data are expressed as the mean \pm standard error of the mean. Student's $t$ test for unpaired 


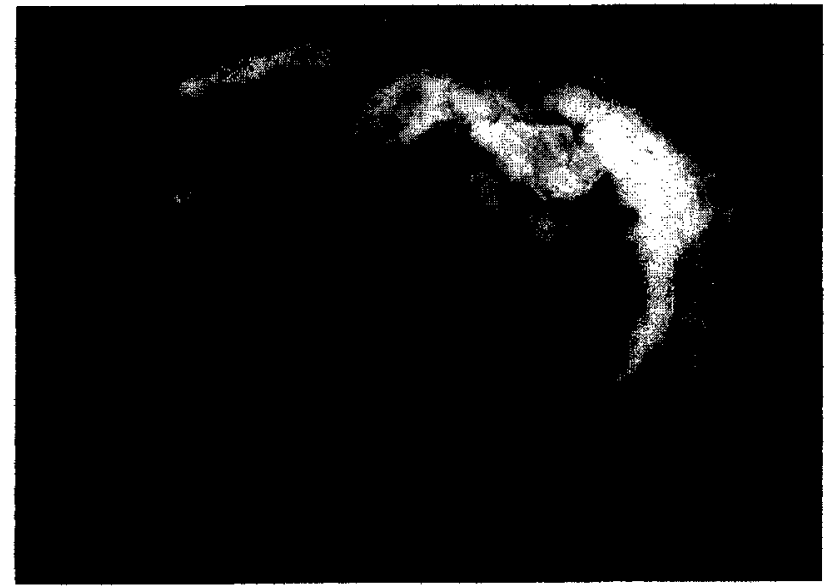

Fig. 4. Representative heart slice from a control animal after LCX thrombosis and subsequent staining with triphenyltetrazolium. The pale white areas, representing infarcted tissue, characteristically involve the free posterior wall and the posterior papillary muscle (top). The nearly obliterated cavity on the left is the right ventricle.

Table I. Effect of nafazatrom (BAYg6575) on coronary blood flow

\begin{tabular}{ccc}
$\begin{array}{c}\text { Mean coronary } \\
\text { blood flow } \\
(\mathrm{ml} / \mathrm{min})\end{array}$ & $\begin{array}{c}\text { BAYg6575 } \\
(n=8)\end{array}$ & $\begin{array}{c}\text { Saline } \\
\text { solution } \\
(n=9)\end{array}$ \\
\hline $\begin{array}{l}\text { Pre-LCX stimulation } \\
\text { End stimulation }\end{array}$ & $21 \pm 1.6^{*}$ & $21.1 \pm 1.5$ \\
\hline
\end{tabular}

$* \mathrm{X} \pm \mathrm{SE}$.

$+p<0.05$.

observations was used to evaluate the statistical significance of the hemodynamic and infarct data. The MannWhitney test was used to evaluate the statistical significance of the arrhythmia and platelet aggregation data. A p value of $<0.05$, treated vs control animals, was considered a significant difference.

\section{RESULTS}

Effects of LCX injury on coronary blood flow in nontreated control dogs. The typical time course of events which occurs in response to intimal injury to the LCX in the conscious dog is shown in Fig. 2. ECG changes manifested as either ST segment depression or elevation are accompanied by abrupt interruptions in coronary artery blood flow which initially occur in a cyclic pattern and finally culminate in a total cessation of LCX flow. The mean time to occlusion is 9 hours when a current intensity of $\mathbf{5 0}$ $\mu \mathrm{A}$ is employed. Fig. 3 depicts a typical thrombus from a control dog in which the vessel lumen was totally occluded and in which LCX flow was zero. ECG changes typical of ischemic injury and subsequent myocardial infarction were observed upon
Table II. Effect of nafazatrom (BAYg6575) on coronary thrombosis and infarction

\begin{tabular}{lcc}
\hline & $\begin{array}{c}\text { BAYg6575 } \\
(n=9)\end{array}$ & $\begin{array}{c}\text { Saline } \\
\text { solution } \\
(n=9)\end{array}$ \\
\hline $\begin{array}{l}\text { Thrombus wet weight } \\
(\mathrm{mg})\end{array}$ & $7.6 \pm 1.9^{*}$ & $16.7 \pm 3.7$ \\
$\begin{array}{l}\text { Infarct (gm) } \\
\text { Left ventricle (gm) }\end{array}$ & $\begin{array}{c}70.6 \pm 1.5 \dagger \\
\text { Infarct left ventricle } \\
\left(\begin{array}{c}(0.9) \\
\text { Total heart (gm) }\end{array}\right.\end{array}$ & $10.4 \pm 1.2$ \\
\hline
\end{tabular}

${ }^{*} \mathrm{X} \pm \mathrm{SE}$

$\dagger p<0.05$.

Table III. Effect of nafazatrom on ventricular arrhythmias after LCX stimulation

\begin{tabular}{ccc}
\hline & \multicolumn{2}{c}{ PVC/heart rate (\%) } \\
\cline { 2 - 3 } Hours & $\begin{array}{c}\text { BAYg6575 } \\
(n=9)\end{array}$ & $\begin{array}{c}\text { Saline solution } \\
(n=9)\end{array}$ \\
\hline $0-6$ & $1 \pm 2^{*}$ & $4 \pm 9$ \\
$7-12$ & $12 \pm 15$ & $28 \pm 11$ \\
$13-18$ & $36 \pm 12 \dagger$ & $75 \pm 11$ \\
$19-24$ & $37 \pm 12 \dagger$ & $98 \pm 2$ \\
\hline
\end{tabular}

PVC $=$ premature ventricular contractions.

$* \mathrm{X} \pm \mathrm{SE}$.

$\dagger p<0.05$.

analysis of the recorded ECG data. Fig. 4 is a transverse section from one of the hearts in the control group. Staining with triphenyltetrazolium chloride reveals an area of unstained tissue in the distribution of the LCX, which had undergone thrombotic occlusion. A summary of the data from the group of saline-treated control animals is contained in Tables I, II, and III.

Effects of nafazatrom in animals subjected to LCX injury. The acute administration of nafazatrom had no effect on heart rate, blood pressure, ECG morphology, or coronary blood flow. There was a trend for blood pressure to be decreased in some animals at the end of the observation period just before the time of death; however, the number of animals was too few for meaningful comparisons. Both electrical stimulation of the LCX and the mean coronary blood flows of the control and drug-treated groups were the same $(21.1 \pm 1.5$ vs $21 \pm 1.6 \mathrm{ml} / \mathrm{min})$. At the end of LCX stimulation, the mean coronary blood flow was significantly greater in the drugtreated group than in the control group (Table I). For both groups, the reduction in mean coronary blood flow after LCX stimulation was significant as compared to the respective baseline states. 


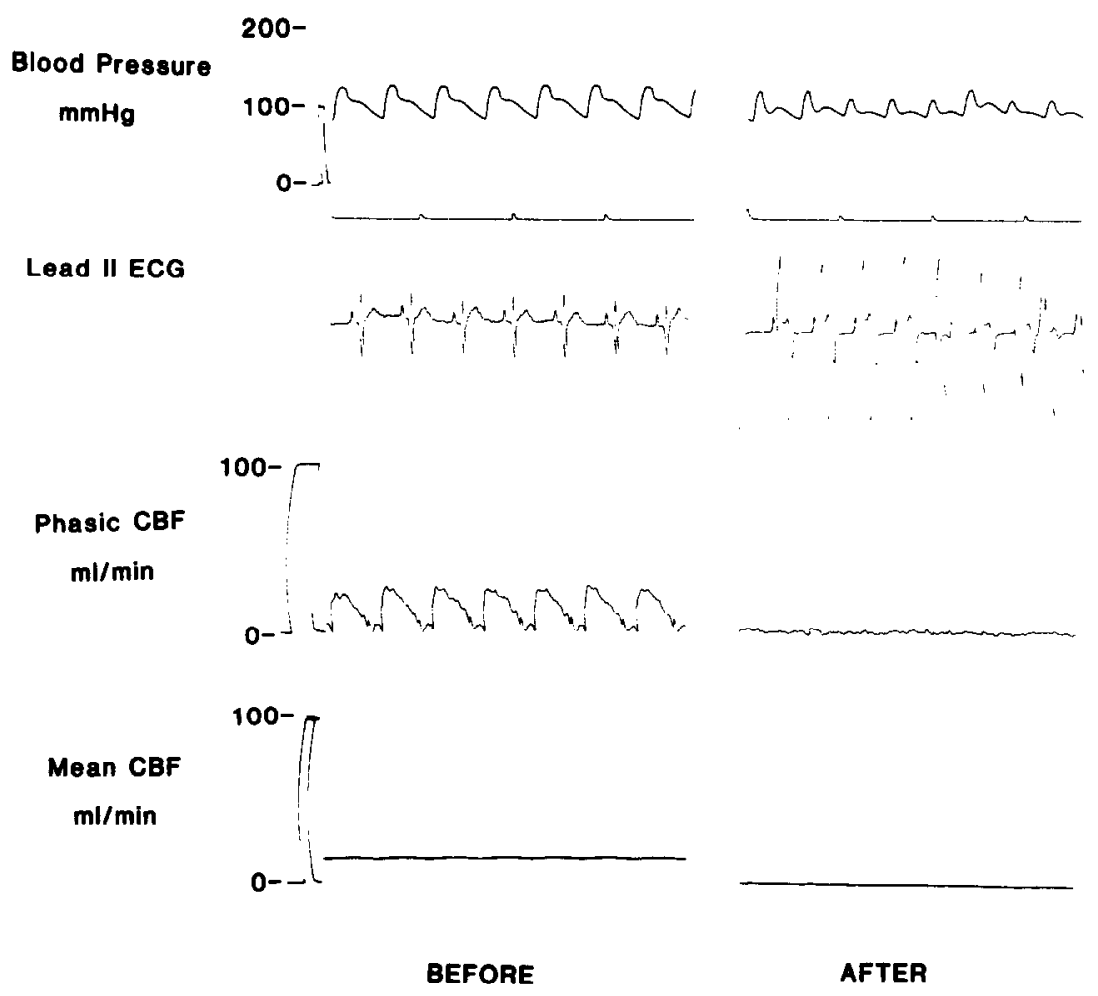

Fig. 5. Representative hemodynamics from a control animal treated with saline- $\mathrm{NaOH}$. The "before" tracing represents the postsurgical recovery period before drug treatment or electrical stimulation. The "after" tracing represents the period after both drug treatment and 24 hours of electrical stimulation of the LCX.

Thrombus wet weight was significantly smaller in the drug-treated group than the control group ( $\mathrm{Ta}$ ble II). Drug-treated animals tended to have smaller thrombi ( $<6 \mathrm{mg}$ ) associated with preservation of coronary blood flow in four animals. In three treated animals, large thrombi (>6 mg) were associated with absence of coronary blood flow. One animal with a small thrombus was associated with absent coronary blood flow, although no obvious focal spasm of the LCX was noted at the time of death. In control animals, all thrombi were associated with absent coronary flow except in one animal where a small thrombus was present with a markedly reduced coronary flow.

Left ventricular infarction was smaller in the drug-treated group than the control group (Table II). This difference was also apparent when infarction was expressed as a percentage of the left ventricular weight to correct for differences in heart weight. In two animals with occlusive thrombi there was minimal evidence of left ventricular infarction. Gross inspection of the heart in these two animals did not reveal extensive collateralization of vessels. Analysis of ventricular arrhythmias revealed signifi- cantly fewer arrhythmias in the drug-treated animals over the last 12 hours of electrical stimulation (Table III). In drug-treated animals, the fewest arrhythmias were noted in those animals with relative preservation of coronary blood flow. Representative tracings of the hemodynamic and ECG effects of drug and control treatment are noted in Figs. 5 and 6 , respectively.

Ex vivo platelet aggregation studies revealed no significant differences between the drug and control groups for the baseline aggregating conditions. In the drug-treated animals, platelet aggregation was significantly inhibited at both 24 and 72 hours when compared to the predrug baseline for two aggregating conditions: collagen and adenosine diphosphate (Fig. 7). No such differences were apparent for the arachidonic acid condition. A representative platelet aggregation curve is noted in Fig. 8. For the control group, a major difference was only apparent between 24 and 72 hours for two aggregating conditions: collagen and arachidonic acid (Fig. 9). No difference was apparent when the 24- and 72-hour values were compared to the predrug baselines for any of the aggregating conditions. 


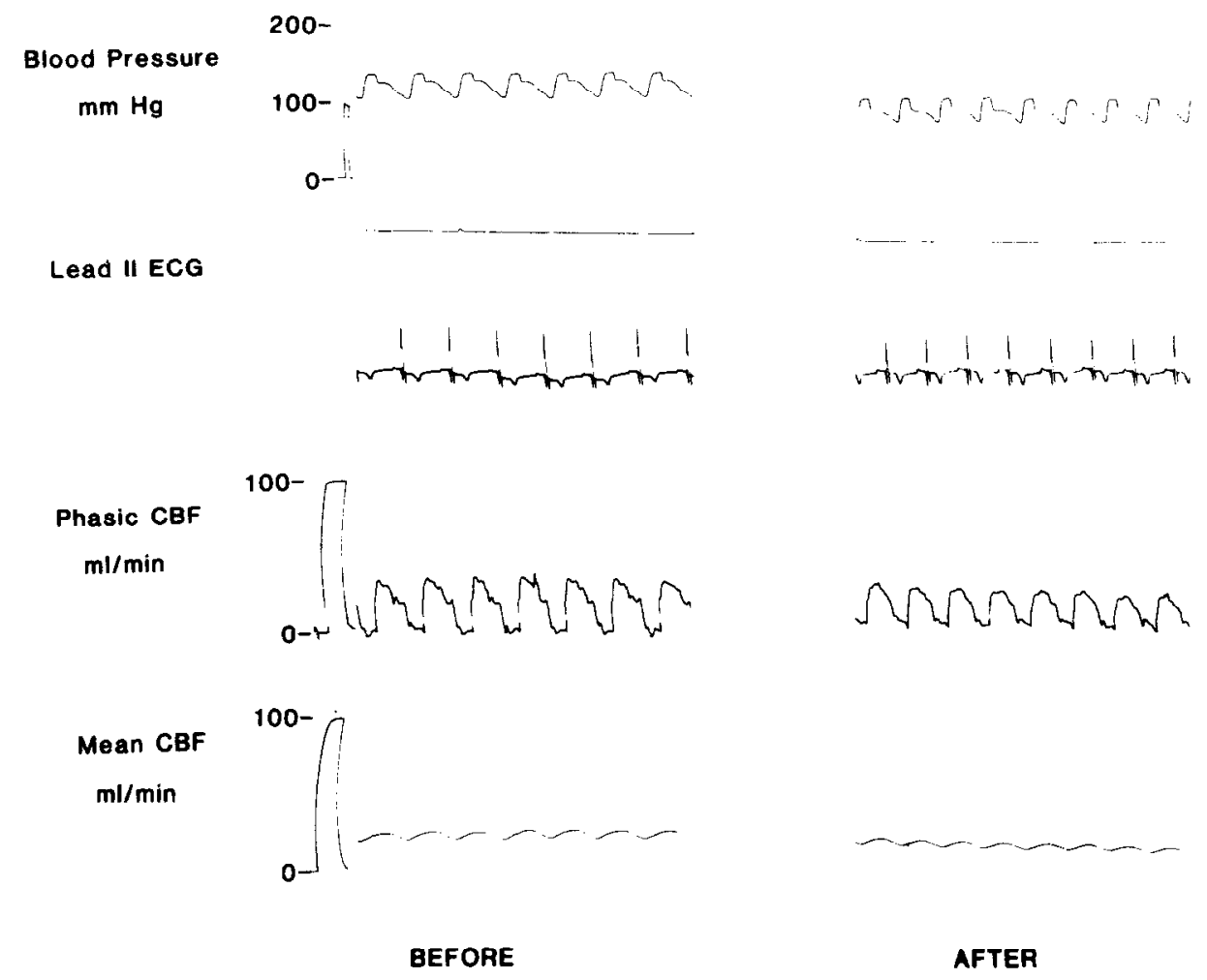

Fig. 6. Representative hemodynamics from an animal treated with nafazatrom (BAYg6575), $1 \mathrm{mg} /$ $\mathrm{kg} /$ every 6 hours intravenously. The "before" tracing represents the postsurgical recovery period before drug treatment or electrical stimulation. The "after" tracing represents the period after both drug treatment and 24 hours of electrical stimulation of the LCX.

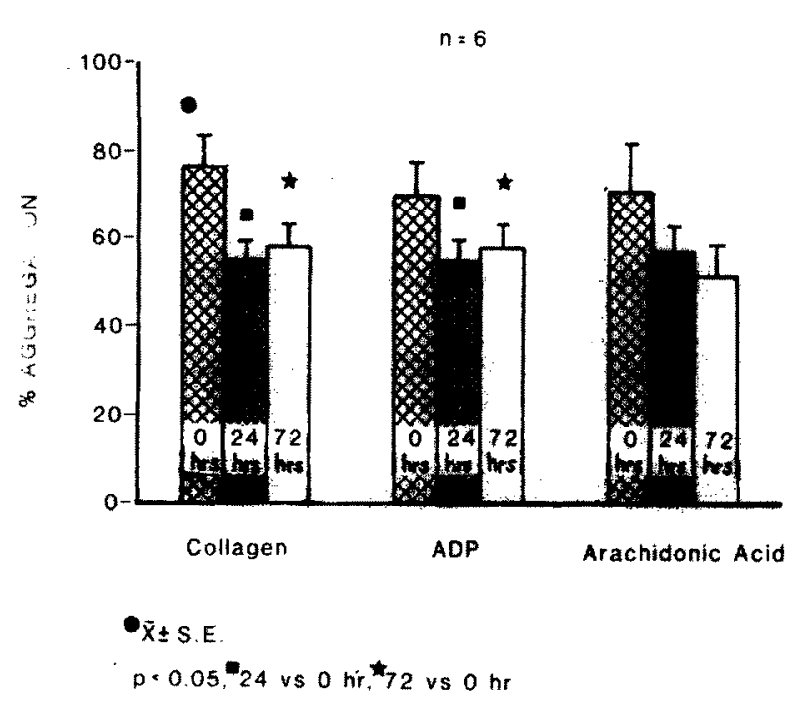

Fig. 7. Effect of nafazatrom (BAYg6575) on ex vivo platelet aggregation. Each bar represents the mean $\pm \mathrm{SE}$ for an aggregating condition at one of three time points: 0 $h r s=$ predrug baseline; $24 h r s=$ after 24 hours of drug therapy; $72 \mathrm{hrs}=$ after 72 hours of drug therapy, the last 24 hours of which includes the period of LCX electrical stimulation.

\section{DISCUSSION}

The hemodynamic effects of nafazatrom were negligible during acute administration as has been previously reported. ${ }^{9}$ This result is not surprising if one considers the proposed mode of action, that is, nafazatrom is not a prostacyclin agonist; rather it increases the availability of native prostacyclin. Our studies did not specifically evaluate the chronic hemodynamic effect of nafazatrom, although there was a trend for the blood pressure to be lower for some animals at the time of death. These results could be due to the effects of nafazatrom, hypovolemia, or myocardial infarction, and thus we cannot comment on their significance.

Nafazatrom effect on coronary blood flow. At the end of the experimental period (after electrical stimulation of the LCX), the coronary blood flow was greater in the treated animals than control animals. The preservation of coronary blood flow seemed to be related to the size of the arterial thrombus; larger thrombi were associated with smaller flows while small thrombi had a negligible 


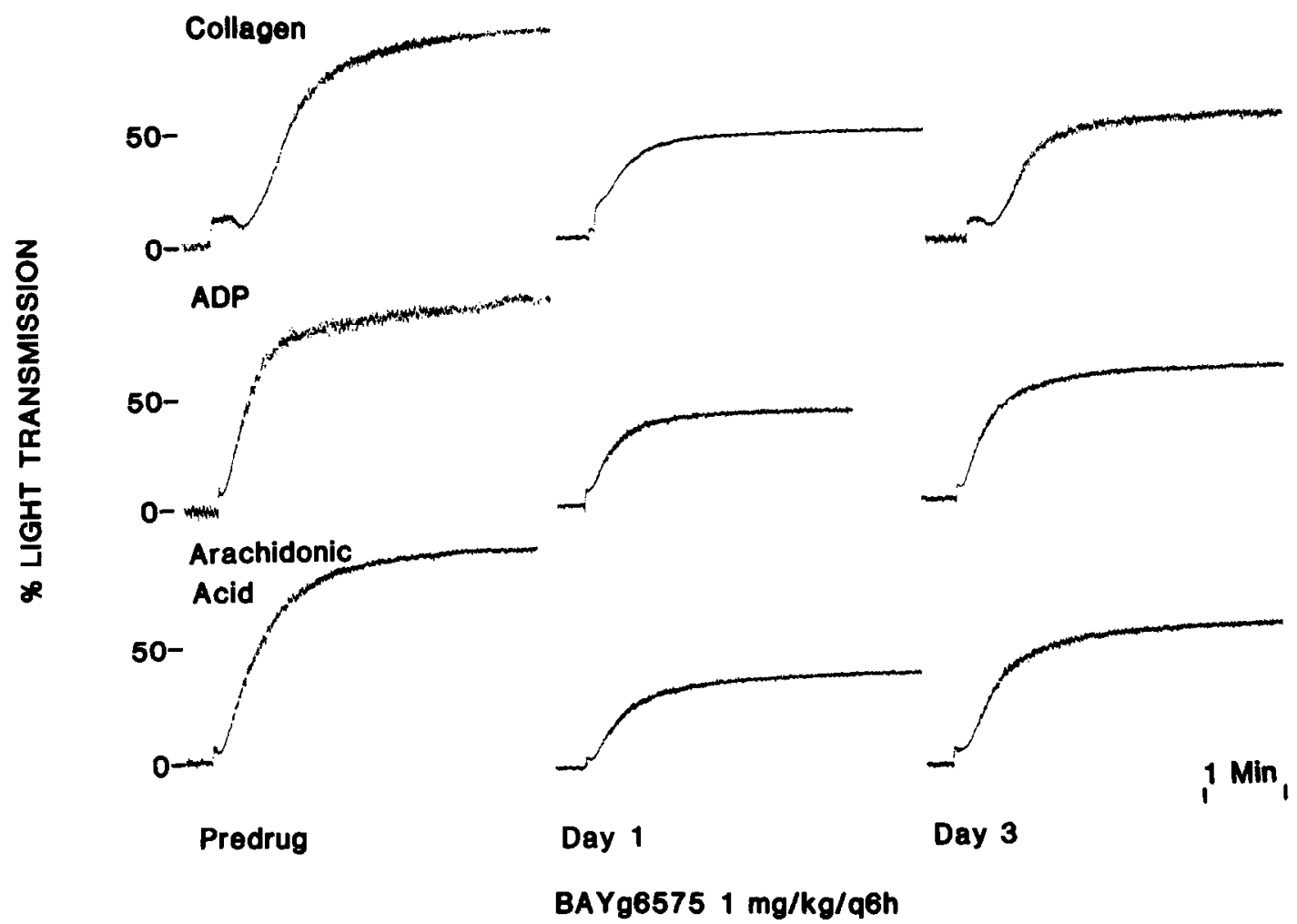

Fig. 8. Effect of BAYg6575 on ex vivo platelet aggregation. Representative platelet aggregation curves for a nafazatrom (BAYg6575)-treated animal in response to three aggregating conditions. Time points include predrug baseline, day 1 after 24 hours of drug therapy, and day 3 after 72 hours of drug therapy including 24 hours of electrical stimulation of the LCX.

effect on coronary blood flow. It is not entirely clear what the primary drug effect is, that is, relief of coronary spasm or inhibition of thrombosis. It is possible that both events occur to some extent, and the drug may be affecting both processes.

Diltiazem, a calcium channel blocker with prominent vasodilatory properties, has been evaluated in this coronary thrombosis model and appears to have no antithrombotic effects. ${ }^{10}$ This would argue for the relative importance of the process of thrombosis in our model. However, one animal in the nafazatromtreated group had a very small thrombus $(\sim 1 \mathrm{mg}$ ) associated with absent coronary blood flow, arguing for the potential importance of coronary spasm, at least in some animals. It seems likely that the beneficial effect of nafazatrom in preventing thrombosis while maintaining coronary blood flow has several facets: an increase in prostacyclin with its attendant antiaggregatory and vasodilatory properties; inhibition of lipoxygenase with attendant decreased production of vasoconstricting leukotrienes, and the poorly understood thrombolytic effect.
In the early stages of electrical stimulation there are several episodes of marked reduction of coronary blood flow followed by marked reactive hyperemia. Several such episodes will occur before the vessel becomes totally occluded. These episodes most likely represent transient thrombotic occlusion of the coronary vessel with subsequent distal microembolization of the fragmented thrombi. ${ }^{11}$ In both our drug-treated and control animals, these same events occur. The drug-treated animals have smaller thrombi at the site of intimal injury than control animals; however, the total amount of thrombus formed is unknown since some thrombus is embolized downstream. One can only speculate that the drug-treated animals' thrombi are less deleterious as judged by end points such as coronary blood flow or myocardial infarction (vide infra). It is important to recognize that the anodal current of $50 \mu \mathrm{A}$ applied to the intimal surface of the circumflex vessel does not generate sufficient heat to produce protein denaturation and that the resulting thrombus mass is due to an interaction of the platelet with the denuded surface of the vessel. ${ }^{6}$ 


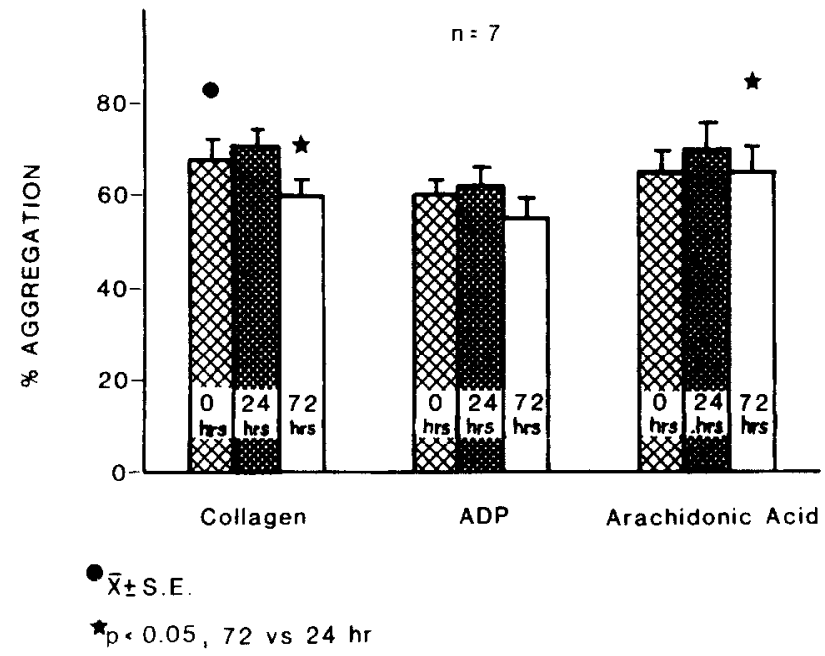

Fig. 9. Effect of saline- $\mathrm{NaOH}$ on ex vivo platelet aggregation. Each bar represents the mean $\pm \mathrm{SE}$ for an aggregating condition at one of three time points: $0 \mathrm{hrs}=$ predrug baseline; $24 \mathrm{hrs}=$ after 24 hours of drug therapy; 72 $h r s=$ after 72 hours of drug therapy, the last 24 hours of which includes the period of LCX electrical stimulation.

Reduction in ultimate infarct size. Drug-treated animals had smaller left ventricular infarctions as compared to the control group. Maintenance of epicardial coronary blood flow is of major importance in this regard. However, two animals had occlusive thrombi yet there was minimal evidence of infarction. While extensive collateral networks were not evident in the two animals cited, functional collateral recruitment can occur, conceivably due to or independent of a drug effect. Within the ischemic zone as well as the border of the ischemic zone, prostacyclin may act not only as a vasodilator but also as an inhibitor of platelet microthrombus formation. An additional intriguing property of nafazatrom is its effect as a free radical scavenger, which may act to preserve ischemic myocardium. ${ }^{3}$ It would be of interest to study nafazatrom further in global ischemia or one of the occlusion-release models of experimental infarction to further delineate its effects on protecting against ischemic myocardial injury. ${ }^{12}$

Ventricular tachyarrhythmias. The frequency of ventricular arrhythmias in drug-treated animals was reduced over the last 12 hours of study. In our thrombosis model, total occlusion of the vessel usually occurs approximately 8 to 12 hours after initiation of electrical stimulation followed by ventricular arrhythmias 1 to 2 hours later. The beneficial effect in the drug-treated group reflects the expected time course as we do not expect to see major ventricular arrhythmias before 6 to 12 hours of stimulation.
Understandably, the beneficial effect is most evident in those animals with preserved coronary blood flows and small left ventricular infarctions. Some animals with minimal evidence of decrease in coronary flow and left ventricular infarction will manifest ventricular arrhythmias. These animals will often have thrombosis of one of the distal LCX or marginal branches detected at necropsy. Our experimental protocol suggests that the decrease in ventricular arrhythmias in drug-treated animals is due to the lack of occlusive thrombosis of the LCX. We cannot exclude a primary antiarrhythmic effect of nafazatrom independent of its effects on the arachidonic acid pathway.

Previous studies of nafazatrom on platelet function have indicated no effect on in vitro or ex vivo platelet aggregation in the rat, rabbit, or human. ${ }^{1,4}$ Our studies of ex vivo platelet aggregation in dogs indicate significant inhibition of platelet aggregation in response to collagen and adenosine diphosphate. There was no significant response to arachidonic acid although an inhibitory trend was apparent. In the latter case, the marked variance in the baseline aggregating condition may explain the lack of statistical significance.

Modification of platelet reactivity. The inhibition of platelet aggregation in nafazatrom-treated animals is compatible with several potential mechanisms: an increase in arachidonic metabolites, which inhibit platelet aggregation (e.g., prostacyclin); a decrease in products of the lipoxygenase pathway, which stimulate platelet aggregation (leukotrienes); or inhibition of platelet proaggregatory products (e.g., thromboxane). The previously documented lack of an in vitro effect of nafazatrom in view of our ex vivo platelet aggregation result argues for the nafazatrom-stimulated production of a substance by the organism for the inhibition of platelet aggregation, most likely prostacyclin. The relative role of leukotriene blockade in the inhibition of platelet aggregation is unclear, although in vitro studies in human platelets suggest an important role. ${ }^{13}$ It is unclear why we noted inhibition of platelet aggregation while others have not. Differences may lie in methodology or in the species tested: the dog in our model, and rat, rabbit, and humans in other reports. Our studies also differ in that the drug was given for 72 hours before ex vivo testing of platelet function.

For control animals there was no difference in the aggregation responses at 24 and 72 hours as compared to the baseline predrug response; however, there was an increase in the 24-hour aggregation response relative to the baselines for collagen and 
arachidonic acid. There were also significant differences between the 24- and 72-hour aggregation responses. It is unlikely that the responses are due to hyperaggregable platelets in the postoperative period (e.g., due to tissue injury) as one would expect the predrug baselines to be higher. These results are of uncertain significance.

Conclusions. We have demonstrated beneficial antithrombotic effects of nafazatrom in an experimental model of coronary thrombosis. With inhibition of coronary thrombosis, we noted a relative preservation of coronary blood flow and a decrease in the degree of infarction and frequency of ventricular arrhythmias as compared to control animals. Concomitant ex vivo platelet aggregation studies suggest that the antithrombotic effect is, in part, related to inhibition of platelet aggregation.

\section{REFERENCES}

1. Vermylen J, Chamone DA, Verstraete M: Stimulation of prostacyclin release from vessel wall by BAYg6575, an antithrombotic compound. Lancet 1:518, 1979.

2. Wang PT, McGiff J: Nafazatrom (BAYg6575), an antithrombotic and antimetastatic agent, inhibits 15-hydroxyprostaglandin dehydrogenase. Symposium on Nafazatrom (BAYg6575). Port Chester, New York, 1981.

3. Busse WD: Fffect of nafazatrom on guaiacol peroxidation and arachidonate metabolism in blood cells and microsomes. Symposium on Nafazatrom (BAYg6575). Port Chester, New York, 1981.

4. Seuter F, Busse WD, Meng K, Hoffmeister F, Moller E, Horstman H: The antithrombotic activity of BAYg6575. Arzneimmittelforsch 29:54, 1979 .

5. Carreras LO, Chamone DAF, Klerckx P, Vermylen J: Decreased vascular prostacyclin $\left(\mathrm{PGI}_{2}\right)$ in diabetic ratsstimulation of $\mathrm{PGI}_{2}$ release in normal and diabetic rats by the antithrombotic compound BAYg6575. Thromb Res 19:663, 1980.

6. Romson JL, Haack DW, Lucchesi BR: Electrical induction of coronary artery thrombosis in the ambulatory canine: A model for in vivo evaluation of antithrombotic agents. Thromb Res 17:841, 1980.

7. Vatner SF, Braunwald E: Cardiovascular control mechanisms in the conscious state. N Engl J Med 293:970, 1975.

8. Mills D, Roberts G: Membrane active drugs and the aggregation of human blood platelets. Nature 213:35, 1967.

9. Seuter F: The pharmacology of BAYg6575, an antithrombotic agent (Investigators Brochure Draft).

10. Shea MJ, Bush LR, Romson JL, Driscoll EM, Lucchesi BR: The effect of diltiazem on coronary thrombosis in the conscious canine. Eur J Pharmacol 77:67, 1982.

11. Folts J: Personal communication.

12. Romson JL, Bush LR, Jolly SR, Lucchesi BR: The cardioprotective effects of ibuprofen in experimental regional and global myocardial ischemia. J Cardiovasc Pharmacol 4:187, 1982.

13. Dutilh CE, Haddeman E, Don JA, ten-Hoor F: The role of arachidonic lipoxygenase and fatty acids during irreversible blood platelet aggregation in vitro. Prostaglandins Med 6:111, 1981 . 